\title{
An Open-Ended Work System Knowledge Model for Visualizing, Organizing, and Accessing Knowledge about Information Systems in Organizational Settings
}

\author{
Steven Alter \\ University of San Francisco \\ alter@usfca.edu
}

\begin{abstract}
This essay presents a new approach for visualizing and organizing IS-related knowledge and expanding that knowledge. It mentions several approaches that might seem relevant before proposing a new approach that combines ideas from two sources, a taxonomy of "knowledge objects" (KOs) and the work system perspective (WSP), including several new extensions of work system theory (WST). Its contribution is the rationale and structure of a work system knowledge model (WSKM) that is potentially useful for organizing a significant fraction of knowledge related to IS.
\end{abstract}

\section{The challenge of IS knowledge}

Scientific progress for a major area within a discipline aims to establish and continually update a body of knowledge (BOK) that identifies and expresses relevant knowledge. Leading IS researchers (e.g., [1]) have noted major challenges of establishing an ISBOK. Even with existing IS textbooks and AIS curriculum guides, stubborn issues that impede progress include multiple inconsistent definitions of central concepts, minimal research that tries to overcome the lack of an ISBOK, lack of connection between IS research and IS practice, and rapid technological and social change.

It is no secret that the common terms are used with different meanings in the IS literature, creating a barely contested "Tower of Babel problem" [2]. Two decades ago, [3] discussed how system, user, IS project, implementation, reengineering, requirements, and solution took on quite different meanings in a set of early papers in CAIS. In 2008, [4] identified 20 definitions of IS that ranged from social system to totally automated system. In 2015, [5] identified 34 definitions of IS in the categories, social, sociotechnical, technical, and process. Concerning system, a term that is part of the name of the field, [6, p. 339] said "it is no exaggeration to describe most IS researchers as having used the term 'system' or 'systems' to refer to just about anything that involves electronic information processing." Discussions of service in the IS field exhibit a similar divergence, with diverse definitions emphasizing actions performed for others, value cocreation, commitments, and responses to requests from computerized entities. The minimal concern (with some exceptions mentioned here) about clarifying basic concepts may have contributed to the occurrence of a debate in CAIS discussing whether IS is a science [7]. One of the hallmarks of a science is a reasonable level of clarity and shared concern about creating and applying deep and integrated views of major topics.

Goal and approach. This paper's goal is to present the rationale and structure of a work system knowledge model (WSKM) that constitutes a plausible approach for making progress toward an ISBOK, i.e., an organized set of ideas that are useful for understanding, analyzing, evaluating, and communicating about ISs that may be sociotechnical or totally automated. The proposed WSKM focuses on an essential part of the IS field, i.e., the creation, operation, and evolution of ISs in organizations. It omits or treats as tangential other important topics that are studied by IS researchers, e.g., the operation of IT groups, business/IT alignment, the nature of competition, the nature of $\mathrm{AI}$, electronic games, non-business use of social media, and so on.

Requirements for the WSKM include:

1) Internal coherence. Knowledge within the WSKM should fit together in an understandable manner. A minimally structured glossary, index, or set of documents would not suffice.

2) Coverage. Coverage of both sociotechnical ISs (with human participants) and totally automated ISs (where computers perform all of the work other than IS creation and maintenance).

3) Facets. Non-trivial coverage of facets of work often associated with IS, such as making decisions, communicating, coordinating, etc.

4) Inheritance. Use of inheritance from general to special cases to minimize redundancy and to support efficiency in creating an ISBOK.

5) Open-endedness. The possibility of extension in any direction that will increase the WSKM's usefulness for understanding WSs of all types.

The proposed WSKM applies to WSs in general and to special cases of WSs such as ISs and projects. The term 
knowledge model is used instead of ontology, metamodel, or conceptual model because the WSKM includes concepts, generalizations, and other types of knowledge, not just concepts, and because it is designed to be expandable and to permit overlaps that formal ontologies try to prohibit.

The two sources of the proposed WSKM are: 1) a taxonomy of "knowledge objects" (KOs) and 2) the work system perspective (WSP), which builds on work system theory (WST) and its extensions. The WSKM assumes that most types of KOs could apply to the main components of WST and ideas in its extensions. A complete and thoroughly tested version of the WSKM could support both IS teaching material and interactive tools built on those ideas, such as those appearing in [8]. The WSKM applies a metamodel's emphasis on concepts and relationships but does not try to define constraints or other limitations on models. It is not designed for automated inference or automated model verification. It is designed to help analysts, stakeholders, and/or researchers find and apply KOs that may support their deliberations about systems in organizational settings. That calls for flexibility and for recognition that parts of relevant formal or informal models may apply KOs that are not included in the WSKM.

Organization. The next section identifies and notes limitations of alternative starting points for pursuing this paper's goal from different directions. Subsequent sections summarize the WSP and the taxonomy of KOs, both of which have been explained elsewhere but have not been combined as the basis of the rationale and structure of a WSKM that could be a starting point for producing an ISBOK. The treatment of WSP uses ideas that are generally not associated with the WST core of the WSP, such as facets of work, interactions between WSs, and functions performed by WSs for other WSs. The discussion of the proposed WSKM includes three tables illustrating its content through may examples. The conclusion identifies next steps.

Like many essays introducing a new view of a topic, this paper does not use a formal methodology and is not based on a DSR-style procedure. Instead, it relies on its specification of the issue at hand (proposing a WSKM as part of a path toward an ISBOK), its explanation of the underlying ideas (WSP and a taxonomy of KOs), its explanation of the rationale and structure of the proposed WSKM, and a final section that identifies next steps toward the goal.

\section{Alternative ISBOK approaches}

This paper combines WSP with a taxonomy of KOs as a starting point for pursuing an ISBOK. This section mentions several other possible approaches.
Market of ideas. One possibility is that the IS field is so diverse that it is best described as a market of ideas [9] with different ideas attracting attention in different areas of an intellectual marketplace. That approach would make it difficult to produce a coherent ISBOK because there would be little motivation to create overarching views that lead to coherence.

Ontologies, conceptual models, metamodels. [10, p. 4] compares "a wide spectrum of information artifacts that [have been] ... classified as ontologies" using a dimension from lower to higher complexity. Artifacts along that dimension include a catalog, a set of files, a glossary, a thesaurus, a collection of taxonomies, a collection of frames (from AI research decades ago), and sets of general logical constraints. With taxonomies, "properties of more general classes are inherited by the more specific ones. Frame-based systems [add] ... relations between objects and restrictions on what and how classes of objects can be related to each other. Ontologies use the axioms of full first order, higher order, or modal logic."

Conceptual models are "explicit descriptions of mental models. They are information objects ... that rely on a modeling language to describe any aspect of a domain of interest for purposes of understanding and communication." [11]. A metamodel is conceptual model that defines modelling concepts to be used in conceptual models [12], in effect, operating at a level higher than the conceptual models that they govern.

This paper uses the term knowledge model to bypass distinctions between ontologies, metamodels, and conceptual models that go beyond its purposes.

Notable research directed toward ISBOK issues. Four examples help in visualizing possible paths not taken by the WSKM approach: 1) representation theory, 2) the AIS "Theories Used in IS Research Wiki," 3) compilation and organization of important articles, and 4) of constructs for IS research.

Representation theory. An approach proposed by [13 p. 62)], later called representation theory [14], says that an IS is a representation of a real-world system and ISs "are primarily intended to model the states and behavior of some existing or conceived real world system." Representation theory applied the BungeWeber-Wand (BWW) ontology and energized important research [14] but, as noted in [13, p. 62)], omits many important IS topics such as how an IS is implemented, used, or managed. Seeing an IS as a representation of the world ignores many IS purposes covered by WSKM, such as automating specific tasks, making suggestions, controlling work, and so on.

The "Theories Used in IS Research Wiki" [15] summarizes many such theories, often without clarifying their domains, possibly because many are not specifically about IS, e.g., the theory of reasoned action 
and theory of planned behavior, which are not fundamentally about IS. Similarly, the WSKM assumes that an ISBOK cannot avoid including KOs from areas outside of IS per se. In contrast with the wiki, the WSKM includes KOs that are not theories.

Compilation and organization of important articles. A quite different approach tries to compile knowledge in the form of published articles. [16] relies on classification in proposing an IS Development BOK (ISDBOK) based on textual analysis covering 6643 Senior Scholars' Basket of Eight articles between 1978 and 2012. The result is "466 ISD articles that offer canonical ISD knowledge distinctive to IS and complementary to other disciplines." While the 466 articles are categorized into useful categories, technical and societal change surely imply that many of those articles are obsolete in some ways and in combination likely contain important inconsistencies and omissions.

Compilation and organization of constructs. [17] applied natural language processing algorithms for detecting whether two behavioral constructs refer to the same real-world phenomenon. Application to 193 articles in two Basket of Eight journals between 1983 and 2009 led to a construct taxonomy including 1004 constructs in 19 hierarchies such as IT adoption (412 constructs), IS development (102), trust (63), task/job (45), and so on. [17] organized a set of research constructs but did not explain how the 19 categories fit together as a coherent approach for understanding ISs.

Systems theories. The WSKM is based on WST. Two other systems theories are noted here for contrast.

"General Systems Theory (GST) integrates a broad range of special systems theories by naming and identifying patterns and processes common to all of them. By use of an overarching terminology, it tries to explain their origin, stability and evolution." [18, p. 16]. GST assumes that "a system is not something presented to the observer, it is something to be recognized by him/her. ... [as] "a way of organizing our thoughts about the [real world]." (p. 16). While "many of the key insights from general systems thinking have become part of the IS lexicon." [19, p. 128], general discussions of system properties included in GST often provide little nonobvious help in defining and describing "the system" in situations involving organizations and human activity.

Use of sociotechnical systems theory in IS proves illusive even though the IS field is often viewed as sociotechnical. A review of $M I S Q$ and ISR papers between 2000-2016 [20] argues that IS research has lost sight of its sociotechnical character. Trying to use sociotechnical theory as the core of an ISBOK is problematic because it exists in at least four major variants [21], and distinctions between STS theory, STS design, and STS change [22]. [23, p. 317] sees STS design as "more a philosophy than a methodology" ... that "tried to achieve its two most important values: the need to humanize work through the redesign of jobs and democracy at work" (p. 321).

\section{The work system perspective}

The proposed WSKM builds on work system theory (WST), the core of the work system perspective (WSP). This section summarizes WST and the related work system method (WSM). It also summarizes extensions of WST that are important in the WSKM.

\subsection{Work system theory}

Terminology and other aspects of WSP evolved over several decades. Various confusions were addressed when [24] designated WST as the core of the WSP, distinct from extensions of WST that focus on service systems, workarounds, compliance and noncompliance, work system axioms, design principles, system interactions, facets of work, alternative metamodels, and so on. WST consists of the definition of WS, the WS framework (Figure 1), and the WS life cycle model (WSLC - Figure 2). Some of the extensions are relevant to the proposed WSKM.

Definition of WS. A WS is a system in which human participants and/or machines perform work (processes and activities) using information, technology, and other resources to produce specific product/services for internal and/or external customers [24]. The first and/or addresses trends toward automation of work by saying that work systems may be sociotechnical or totally automated (in contrast with assuming that the IS discipline is about sociotechnical systems). A WS usually is named based on what it accomplishes and not based on software that it uses.

WS framework: a basic understanding of a WS. The nine elements of the WS framework outline a basic understanding of a WS's form, function, and environment during a period when it retains its identity even though incremental changes may occur, such as minor personnel substitutions or technology upgrades. The WS framework is an informal representation of a domain ontology. Processes and activities, participants, information, and technologies are completely within the WS. Customers and product/services may be partially inside and partially outside because customers often participate in activities within a WS and because product/services take shape within a WS. Environment, infrastructure, and strategies are treated as outside of the WS even though they have direct effects within a WS. Five bi-directional arrows within the framework highlight the desirability of alignment between specific pairs of elements. The term product/service bypasses distinctions between products and services that are not 
helpful for analyzing operational systems. The term processes and activities is used because activities in less structured WSs often do not operate in a prescribed sequence. The planned change phases of the WSLC (initiation, development, and implementation) can be viewed as separate WSs.

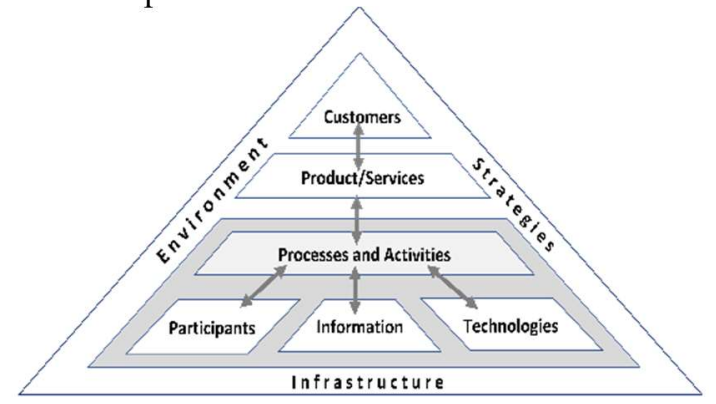

Figure 1: Work system framework

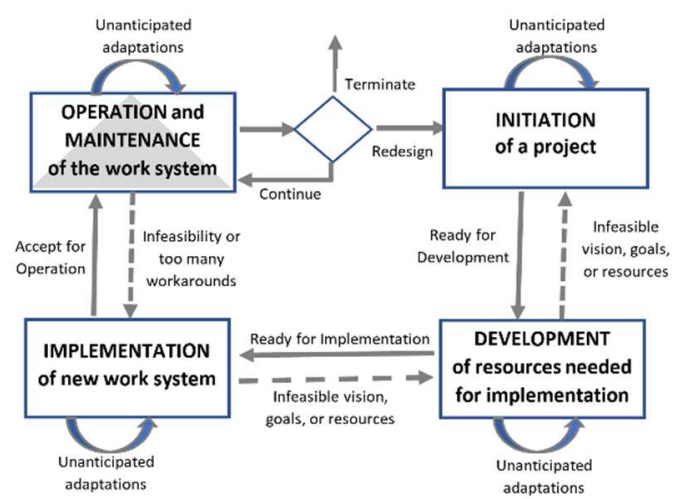

Figure 2: Work system life cycle model

Information systems and projects. IS is a special case of WS. An IS is a WS most or all of whose activities are devoted to capturing, storing, retrieving, deleting, transmitting, manipulating, and/or displaying information. A project (such as ISD) is a WS that is designed to produce specific product/services and then go out of existence. The initiation, development, implementation phases of the WSLC can all be viewed as projects, and hence as WSs on their own right.

Sociotechnical and totally automated work systems. A WS may be sociotechnical (with human participants) or totally automated. Similarly, an IS (a kind of WS) can be sociotechnical (e.g., accountants creating financial statements) or totally automated (e.g., computers generating accounting reports).

Work system method. WST evolved out of several decades of effort in developing the work system method (WSM), a semi-formal systems analysis and design approach that tries to help business professionals visualize WSs in their own organizations and collaborate more effectively with IS/IT professionals. During 2003-
2017, individual students or teams of students (mostly employed MBA and Executive MBA) used various versions of WSM to produce over 700 management briefings recommending improvements of problematic IT-enabled WSs, mostly in their own firms (e.g., [25, 26]). While details differ, every version of WSM is organized as follows: 1) identify the smallest WS that has the problem or opportunity; 2) summarize the "as-is" WS using a WS snapshot, a stylized one page summary; 3) evaluate the WS's operation using measures of performance, key incidents, social relations, and other factors; 4) drill down further as necessary; 5) propose changes by producing a WS snapshot of a proposed "to be" WS that should perform better; 6) describe likely performance improvements.

\subsection{Relevant extensions of WST}

The core of WST (the definition of WS and the frameworks in Figures 1 and 2) is designed to help in attaining a basic understanding of a WS or IS. Some of the extensions of WST bring additional ideas and perspectives that may help practitioners and researchers look at a WS or IS more deeply. Extensions of greatest importance to the WSKM include the following:

Facets. The idea of "facet" is like a facet of a cut gem. It is not a separate component of the gem, but rather a face or aspect that can be observed or analyzed. The idea of facets of work emerged from intermittent research aimed at enriching systems analysis and design. Earlier steps in that research $[27,28]$ failed to produce truly usable conceptualizations. The idea of facets of work is more usable, as illustrated by an example in [29] and several unpublished drafts.

\section{Table 1. 18 facets of activities}

\begin{tabular}{|c|c|c|}
\hline $\begin{array}{l}\text { - Making } \\
\text { decisions } \\
\text { - Communicating } \\
\text { - Processing } \\
\text { information } \\
\text { - Thinking } \\
\text { - Representing } \\
\text { reality } \\
\text { - Providing } \\
\text { information }\end{array}$ & $\begin{array}{l}\text { - Applying } \\
\text { knowledge } \\
\text { - Planning } \\
\text { - Controlling } \\
\text { execution } \\
\text { - Improvising } \\
\text { - Coordinating } \\
\text { - Performing } \\
\text { physical } \\
\text { work }\end{array}$ & $\begin{array}{l}\text { - } \text { Performing } \\
\text { support work } \\
\text { - Interacting } \\
\text { socially } \\
\text { - Providing } \\
\text { service } \\
\text { - Creating } \\
\text { value } \\
\text { - Co-creating } \\
\text { value } \\
\text { - Maintaining } \\
\text { security }\end{array}$ \\
\hline
\end{tabular}

Table 1 lists 18 facets of processes and activities, originally called "facets of work." Associated with all of those facets is a substantial amount of knowledge that should be part of an ISBOK, i.e., specific concepts, evaluation criteria, design trade-offs, sub-facets, and so on. A key point here is that various facets are associated with largely separate sets of concepts, and not whether the most useful number of facets of 14, 18, or 23. Almost every facet included in Table 1 applies to both sociotechnical and totally automated systems. There is 
no assumption that the facets are mutually independent. To the contrary, some facets overlap (e.g., making decisions often involves communicating and processing information). Criteria for inclusion as a facet are based on association with separate sets of useful concepts, evaluation criteria, design trade-offs, and so on. Much of the knowledge related to these facets never appears in systems analysis books and in IS research that is not specifically about these topics in WSs, ISs, or projects.

The WSKM extends the original idea of facet of work by assuming that multiple facets are associated with all nine elements of the WS framework. For example, facets of the WS element participant include actor role, user (of IT), and human worker. Much knowledge related to WS participants is more closely linked to those facets rather than to participant in general. E.g., computer self-efficacy more related to users of IT than to actor role in general because many actor roles do not use computers. Since all nine elements may have facets, the WSKM assumes that KOs may be associated most closely to any type of WS in general, to a specific element of the WS framework, or to a specific facet of an element for any type of WS.

Forces induce or impede specific types of transitions in the state of entire WSs or WS elements. At least five types of forces apply to WSs as a whole: 1) Cohesive forces tend to hold WSs together, e.g., incentives, goals, controls, alignment. 2) Disruptive forces tend to make WSs less organized and may degrade them, e.g., internal misalignments, discontent, poor management, design flaws. 3) Innovative forces encourage changes in WS architecture or operation based on benefits for customers or other stakeholders. 4) Inertial forces resist planned or unplanned changes in WS operation. 5) Forces from a distance (analogous to gravity) include economics, competition, regulation, and technological change. In a similar way, drivers or obstacles to WS change are often related to specific elements of the WS framework [30, p. 8].

Functions. Most WSs (including ISs) perform functions in relation to (other) WSs that they support. These functions are intended behaviors and responsibilities involved with roles, activities, and/or positions in relation to the supported WSs. Accordingly, part of the knowledge about ISs concerns different functions that ISs can perform, such as providing information, providing analysis tools, controlling execution of activities in a supported WS, suggesting decisions, and performing totally automating activities. For the sake of symmetry, the WSKM treats such functions as facets of the WS element product/service.

Interactions between WSs (including ISs) include unidirectional, mutual, or reciprocal actions, effects, relationships, influences, or interplay between two or more WSs. Interactions are not mentioned by the WS framework even though they are essential for the operation of enterprises, but also bring risks, regardless of whether they are intentional or unintentional.
Important knowledge is related to interactions such as concepts related to how one WS supplies another or how two WSs coordinate by sharing resources [31]. In many cases those interactions can be traced to one or several WS elements rather than the WSs as a whole.

Overlaps involve sharing of all or part of specific constituents (or their components) by two or more entities. ISs overlap to varying degrees with WSs that they serve. Sometimes they simply deliver information. In other cases, they absorb a great deal of attention within WSs that they serve, as when physicians providing medical care need to expend effort dealing with problematic EMR systems, often contributing to physician burnout [32]. In other cases, ISs are completely enclosed by WSs they serve, as when a factory's WIP tracking system is a part of the factory.

Uncertainties exist for every WS, IS, and project. Differing degrees of uncertainty may apply to how specific processes or activities will be executed and to the exact form and quality of specific product/services that will be produced. Established process flows may not be followed, especially when business processes are more like activity guidelines than activity rules. The possibility and sometimes likely occurrence of workarounds related to various elements of the WS framework adds to the uncertainties about how WSs will operate and the quality of their performance [33].

\section{Taxonomy of knowledge objects}

Every type of KO in the taxonomy of KOs in Figure 3 (adapted from [34]) is present in the substantial amount of knowledge related to WSs, ISs, and projects of various types. Some of the KOs are related to WSs in general, such as the scalability of a WS. Other KOs are related to elements of the WS framework, such as process speed or required qualifications of participants.

The KO taxonomy in Figure 3 covers both nonabstract and abstract KOs. Non-abstract KOs include facts, examples, stories, and databases. Abstract KOs are subdivided into concepts, generalizations, practices and methods, and buzzwords. Concepts include resources (nouns), actions (verbs), characteristics (adjectives), areas of performance and related metrics (in effect, adverbs), and phenomena. Generalizations include axioms, design principles, theories, frameworks, models, and metamodels.

The term KO might sound unusual, but the similar term information object was used in a paper on conceptual modeling [11] by three prominent experts. The taxonomy assumes that science is the creation, evaluation, accumulation, dissemination, synthesis, and prioritization of KOs, including the reevaluation, improvement, or replacement of existing KOs by other KOs that are more effective for understanding important aspects of the relevant domain. 
Tacit vs. explicit knowledge. While tacit knowledge is obviously important, the taxonomy assumes that scientific knowledge is explicit knowledge that may be non-abstract or abstract.

Non-abstract knowledge. Ignoring the textbook distinction between data, information, and knowledge, we assume that non-abstract knowledge includes facts, stories, examples, and datasets. Such knowledge is important in many situations. For example, valuable and actionable knowledge in many studies of IS risk appears in organized lists of different types of IS risks. Similarly, lists of workarounds in the medical literature could be valuable for designing computerized systems in medical settings. Along similar lines, many medical journals provide valuable observational information about specific cases of medical conditions and/or treatments in specific people or facilities.

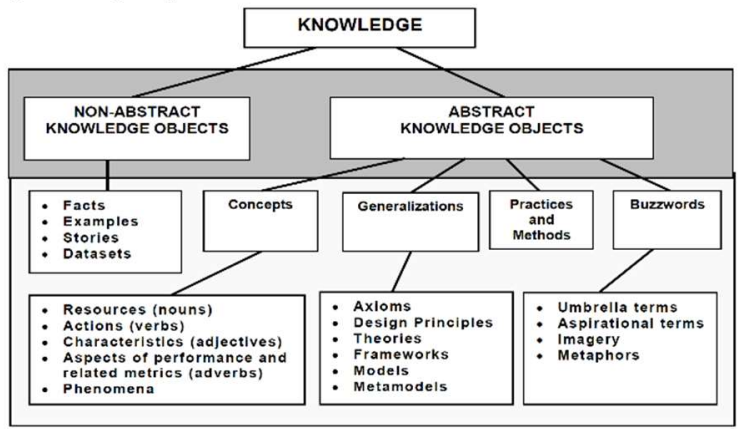

Figure 3: Taxonomy of knowledge objects

Abstract knowledge. This includes concepts, generalizations, practices and methods, and buzzwords, all of which are conceptual artifacts. [35, pp. 64-65)] explains that conceptual artifacts are abstract KOs that can be produced, tested, and improved. Conceptual refers to "discussable ideas, ranging from theories, designs, and plans down to concepts, like unemployment and gravity. Artifact conveys that these are human creations and that they are created for some purpose." Conceptual artifacts have origins and histories; can be described; can be compared with other artifacts; have varied uses; can be valued or judged worthless; may be modified or improved upon; may have unforeseen attributes, uses, or defects that may be discovered; and may be understood and used differently by people with different levels of skill.

Concepts. These range from everyday vocabulary through highly specialized vocabulary used by specific communities of practice. Concepts related to systems may refer to any of the following:

- resources (physical and intangible entities that are used or that perform activities),

- actions (verbs that denote relevant types of actions),

- characteristics (adjectives that describe physical and intangible entities),
- aspects of performance and related metrics (adverbs that describe how well activities are performed),

- phenomena that can be observed, inferred, or imagined as occurring within or across systems.

Practices and methods. These describe how work is performed systematically within a community of practice, i.e., usually as mutually related activities and sometimes as sequences of steps. For example, a review of the agile development literature [36] identified 18 "universal agile practices" including 2) refactoring, 3) customer involvement, 4) unattached communicative teams, 9) time boxing 14) continuous integration/ deployment, and 15) delivering frequent releases. Similarly, [37] identified 22 "lean practices" in manufacturing, such as bottleneck removal, competitive benchmarking, cycle time reduction, lot size reduction, and self-directed work teams. Those examples illustrate that practices and methods are generalized artifacts that must be adapted to details and contexts of situations in which they are applied [11].

Generalizations. These are statements or other representations that are meant to apply to all or most of the entities within a category, such as WSs, ISs, or projects. Six kinds of generalizations in the taxonomy of KOs include axioms, design principles, theories, frameworks, models, and metamodels. Axioms (in this non-mathematical context) are meant to apply to every entity of a specific type within a domain. Axioms within a domain should be mutually independent and mutually non-contradictory. Design principles express desired or beneficial characteristics of designed entities within a domain or sub-domain. Unlike axioms, design principles often have exceptions, may be mutually inconsistent, and may conflict in practice. Organized sets of design principles for sociotechnical WSs have appeared in many journals. Theories, frameworks, models, and metamodels are types of generalizations that often are viewed as overlapping in various ways, The first of Gregor's five types of theory [38] includes frameworks, classification schemas, and taxonomies. The second and third types include models. Some researchers believe that only Gregor Type IV theories qualify as proper theories. This paper bypasses that debate and simply assumes that examples suffice in illustrating what generalization means.

Buzzwords. Buzzwords are metaphorical ideas and imprecise umbrella terms imbued with aspirations and imagery and often viewed pejoratively when used carelessly and without definitions, buzzwords such as artificial intelligence and digital transformation can be classified as a type of knowledge because of their role as organizing visions [39]. 


\section{Work System Knowledge Model}

The proposed WSKM builds on WSP and the KO taxonomy to identify and organize IS knowledge to make it readily available for those who may need it. The WSKM recognizes that multiple KOs of any type might apply to WSs in general or to types of WS such as IS or project, to specific elements of WSs of any type, or to specific facets of any type of WS or of specific elements. Interactions between WSs or between elements of different WSs are also relevant.

Summary of the WSKM. A diagram that tries to trace the WSKM's detailed structure would be awkward because it would need to show so many linkages involving different types of KOs, different types of WSs, different WS elements, and different facets of elements. Instead of a complex diagram, we present an abstract summary of the WSKM and then provide three tables containing illustrative KOs.

The WSKM's structure and purpose can be summarized as follows:

Form. The WSKM is a network of KOs.

Purpose. The purpose of the WSKM is to compile and organize KOs in order to help practitioners and researchers access and use knowledge that is directly and indirectly related to IS.

Omissions. The WSKM is organized around WSs and their interactions. It does not try to organize KOs related to other important topics, e.g., business/IT alignment, the digital divide, or IT-based competition.

Types of KOs. The WSKM's KOs may fall into any of the 19 categories in the taxonomy of KOs (Figure 3 ). Additional types of KOs might be introduced without undermining the WSKM's purpose.

Basis in WST. Work systems are described in the most general way based on WST, which consists of the definition of WS, the WS framework (Figure 1), and the WSLC (Figure 2). Even a limited subset of the WSKM that focuses only on concepts (5 of the 19 KO types) related to WSs in general would probably be quite useful for describing and analyzing systems. Also note that the initiation, development, and implementation phases of the WSLC can be viewed as projects, and therefore as WSs on their own right.

Application levels within a WS. Some KOs apply to an entire WS (e.g., scalability, geographic dispersion). Others apply to specific elements (e.g., accuracy of information or cost to customers for a WS's product/services). Yet others apply to facets of elements (e.g., understandability of communication or criteria for making decisions, both facets of activities). Some KOs that apply at the level of an entire WS also apply to elements, e.g, efficiency of an entire WS or for a process (with efficiency interpreted differently).
Application levels for interactions. In a similar fashion, KOs may apply to interactions within a WS or interactions between WSs. In both cases, they may apply to WSs as a whole or to aspects of specific elements in the WSs.

Types of WSs. ISs and projects are special cases of WSs, but the most fundamental distinction is between sociotechnical and totally automated WSs because KOs describing participants (e.g., skills, ambitions, work/life balance) do not apply to totally automated WSs. ISs may be of either type (e.g., a sociotechnical accounting IS that produces financial statements with the help of a totally automated accounting IS that stores the data and produces reports after accounting decisions have been made). Projects are as sociotechnical today even though some automated WSs proceed with project-like logic.

Inheritance. KOs are inherited by special cases from more general cases. Some inherited KOs may be less useful for some special cases because concepts more associated with special cases may describe that level more effectively. Special cases may also introduce KOs that are not relevant to more general cases.

Coding of an WSKM. The WSKM's network character can be represented in various ways in a computerized tool. Three spreadsheets with individual rows devoted to separate KOs help in visualizing how the relevant data could be stored. The first spreadsheet could focus on KOs for individual WSs. The second spreadsheet, on interactions between WSs. The third would store the hierarchy of WSs ranging from more general to more specialized cases. The rows of the first spreadsheet would include:

1) name of a $\mathrm{KO}$,

2) the type of KO (from Figure 3),

3) the most general type of WS to which the KO applies, e.g., efficiency applies to WSs in general, whereas scrum applies to projects or to software projects, depending on how generally scrum is defined.

4) the application level for a KO, e.g., to a WS as a whole, to a specific WS framework element for a WS, or to a specific facet of an element or WS as a whole.

Visualizing the WSKM. The WSKM can be visualized concretely through illustrative examples such as Tables 2, 3, and 4, which contain small excerpts from what the WSKM could become. Table 2 identifies typical examples of the first four types of concepts (resource, action, characteristics, and area of performance) for sociotechnical WS. Notice how most of the entries apply to all WSs and to sociotechnical ISs. The entries for participants do not apply to all WSs because totally automated WSs do not have participants. (People who create and maintain those WSs are participants in WSs involved with creating and maintaining automated WS). The applicability of most entries to sociotechnical ISs seems to hint that most of 
the basic concepts related to sociotechnical ISs are also concepts related to sociotechnical WSs. In other words, filling in the part of the WSKM for concepts related to sociotechnical WSs in general seems a reasonable starting point for concepts for sociotechnical IS. From the other direction, it might be challenging to find nontrivial concepts that apply to most sociotechnical ISs but do not apply to most sociotechnical WSs.

Table 3 shows examples of phenomena frequently relevant to sociotechnical WSs. Notice that any specific phenomenon might not apply to a specific WS. That is not a problem because the goal is not to produce an exhaustive list of terms that always apply to specific types of situations, especially since those terms would probably be obvious to someone involved with that type of situation. In contrast, the goal here is to organize concepts in a way that makes them easy to access through an app when they are needed.

Generalizations (see Figure 3) could appear in similar tables. For example, the theory of reasoned action, the design principle of "minimum critical specification," and the technology acceptance model could be associated with sociotechnical WSs and would apply to sociotechnical ISs by inheritance.

Practices and methods (Figure 3) such as waterfall, scrum, and rational unified process would not be linked to sociotechnical WSs or ISs in general because many WSs and ISs are not projects and/or do not need software development during periods when they are being studied. Instead, those practices would be linked to projects that involve software development.

Table 4 uses making decisions, one of the facets of the WS element processes and activities, to illustrate the idea that every facet of work brings its own group of associated concepts, evaluation criteria, design tradeoffs, and sub-facets. A greatly expanded version of Table 4 appears in an unpublished draft that includes all 18 facets in seven separate tables illustrating 1) the importance of the facet for understanding systems, 2) the applicability of every facet to sociotechnical and totally automated systems (with the current exception of interacting socially), 3) evaluation criteria, 4) design trade-offs, 5) sub-facets, 6) typical open-ended questions for starting discussions, and 7) application of all of the facets to a previously published case study. Table 4 illustrates that each facet of work links to knowledge that is often relevant but is less directly related to elements of the WS framework. Second, it illustrates the open-endedness requirement mentioned at the outset. The facets of work go beyond the elements of the WS framework. Other groups of concepts could be added in order to maximize flexible applicability when thinking about systems. That spirit of openendedness is quite different from the more restrictive lure of creating conceptual models or metamodels as rigorously designed walled gardens.

\section{Next steps}

This paper pursued its research goal by presenting the rationale and structure of a WSKM that constitutes a plausible approach for making progress toward an ISBOK by consolidating a wide range of KOs related to WSs, and therefore related to ISs. Regardless of whether a formal ISBOK is eventually produced, a computerized version of the proposed WSKM would organize concepts and other IS knowledge to help stakeholders and analysts access knowledge that might help them understand and improve specific systems in organizations. Ideally, a well-developed WSKM would help with the Tower of Babel problem, would help the IS field recognize that knowledge involves much more than theory, and might start to provide a new bridge between research and practice.

Making initial progress. A practical effort to develop a WSKM would likely start with using shortcuts to establish a necessarily incomplete first cut version. That could probably be done in a series of timeboxed sprints (borrowing the term from agile) performed by individuals or small teams. The initial sprint, possibly several days or a week, would create an initial draft that would be evaluated by the individual or group and then updated in subsequent sprints. Ideally that informal process would lead to a third-party comparison and integration of results from unrelated teams. A more formal process building on initial progress could try to incorporate missing KOs from the research literature and from IS-related practice involving IS development and evaluation of operational systems.

Usage. A well-organized set of KOs could be the basis of a set of useful SA\&D apps that could be used to explore issues and propose solutions in real world situations. For example, individuals and teams that used WSM ([25, 26]) would have benefited from using such apps for visualizing and analyzing systems. Many teams did a reasonably good job applying basic WS ideas in highly compressed class projects. Apps based on an organized set of concepts, generalizations, and wellselected examples, likely would have helped them produce better results without much more effort.

Toward an ISBOK. The WSKM assumes that most KOs related to ISs are inherited, i.e., that WSs in general, ISs, and projects share many of the same KOs (especially concepts). That hypothesis could be tested by identifying more than a few non-obvious KOs that apply to all ISs and that do not apply to WSs in general. Pursuing that issue could contribute to discussions about 
whether an ISBOK could or should focus mainly on ideas unique to IS/IT by purposefully omitting ideas from other disciplines.

\section{References}

[1] R. A. Hirschheim and H. K. Klein, "Crisis in the IS field? A critical reflection on the state of the discipline," JAIS, (4), 2003, pp. 237-293.

[2] B. Smith, Ontology. In The furniture of the world (pp. 4768). 2012. Brill Rodopi.

[3] S. Alter, "Same words, different meanings: Are basic IS/IT concepts our self-imposed Tower of Babel?" CAIS, 3(10), 2000, pp. 1-89.

[4] S. Alter, "Defining information systems as work systems: implications for the IS field," EJIS, (17), 2008, pp. 448-469. [5] S.K. Boell, and D. Cecez-Kecmanovic, "What is an information system?" Proceedings of HICSS-48. 2015.

[6] A. S. Lee, "Retrospect and prospect: information systems research in the last and next 25 years," Journal of Information Technology, (25), 2010, pp. 336-348.

[7] K. K. Kautz, "Debate Section Editorial Note: Is Information Systems a Science?" CAIS, 43(1), 2018. p.8.

[8] S. Alter, "Ten Lightweight SA\&D Tools Based on Work System Theory and Its Extensions," AMCIS, 2020.

[9] K. Lyytinen and J. L. King. "Nothing at the center?: Academic legitimacy in the information systems field." JAIS, 5(6), 2004, pp. 220-246

[10] B. Smith and C. Welty. "Ontology: Towards a new synthesis." Formal Ontology in Information Systems 2001, ACM Press.

[11] N. Guarino, G. Guizzardi, and J. Mylopoulos. "On the Philosophical Foundations of Conceptual Models." 29th International Conference on Information Modelling and Knowledge Bases, 2020.

[12] S. Kurpjuweit and R. Winter. "Viewpoint-based Meta Model Engineering," EMISA, Enterprise Modeling and Information System Architecture, 2007.

[13] Y. Wand and R. Weber. "Towards a Theory of the Deep Structure of Information Systems," ICIS 1990.

[14] A. Burton-Jones, J. Recker, M. Indulska, P. Green, and R. Weber.. "Assessing Representation Theory with a Framework for Pursuing Success and Failure. MIS Quarterly, 41(4), 1307-1333.

[15] K. R. Larsen and D. Eargle, (Eds.) "Theories Used in IS Research Wiki," 2018, at http://IS. TheorizeIt.org.

[16] N.R. Hassan, and L. Mathiassen, "Distilling a body of knowledge for information systems development," Information Systems Journal, 28(1), 2018, pp. 175-226.

[17] K.R. Larsen and C.H. Bong, "A Tool for Addressing Construct Identity in Literature Reviews and MetaAnalyses," MIS Quarterly, 40(3), 2016, pp.529-551.

[18] L. Skyttner, "General systems theory: origin and hallmarks." Kybernetes, 25(6), 1996, pp. 16-22.

[19] D. Robey and C. A. Mikhaeil "Déjà Vu or Art Nouveau? A comment on Demetis and Lee's 'Crafting theory to satisfy the requirements of systems science". Information \& Organization, 26(4), 2016, pp. 127-130.
[20] S. Sarker, S. Chatterjee, X. Xiao, and A. Elbanna. "The Sociotechnical Axis of Cohesion for the IS Discipline" MIS Quarterly, 43(3), 2019.695-719.

[21] F. M. van Eijnatten, A. Shani, and M.M. Leary, "Sociotechnical Systems: Designing and Managing Sustainable Organizations," Handbook of organization development, 2008. Sage

[22] D. Austrom, D and C. Ordowich, "North American Design of Nonroutine Work Systems (1980s-1990s), In: Cocreating humane and innovative organizations. Global STS-D Network Press, 2016, pp. 37-51.

[23] E. Mumford, E., "The story of socio-technical design: Reflections on its successes, failures and potential," Information Systems Journal, 16(4), 2006, pp. 317-342.

[24] S. Alter, "Work System Theory: Overview of Core Concepts, Extensions, and Challenges for the Future," JAIS, (14), 2013, pp. 72-121

[25] D. Truex, S. Alter, S., and C. Long. "Systems analysis for everyone else: Empowering business professionals through a systems analysis method that fits their needs." ECIS 2010.

[26] D. Truex, N. Lakew, S.Alter, and S.Sarkar "Extending a systems analysis method for business professionals." In European Design Science Symposium (pp. 15-26). 2011 Springer Berlin Heidelberg.

[27] S. Alter, "Architecture of Sysperanto: A model-based ontology of the IS field." CAIS, 15(1), 2005, pp. 1-40.

[28] S. Alter, "Incorporating more system-related knowledge into systems analysis and design." AMCIS, 2013.

[29] S. Alter, "How Facets of Work Illuminate Sociotechnical Challenges of Industry 5.0." ECIS. 2020

[30] S. Alter, "A systems theory of IT innovation, adoption, and adaptation." ECIS 2018.

[31] S. Alter, "System Interaction Theory: Describing Interactions between Work Systems." CAIS, 2018, 42 (9).

[32] E. Fry and F. Schulte, "Death by a thousand clicks: where electronic health records went wrong." Fortune Magazine, March 18, 2019

[33] S. Alter, S. "Theory of Workarounds, CAIS, 34(55), 2014, pp. 1041-1066.

[34] S. Alter, "Taking Different Types of Knowledge Objects Seriously: A Step toward Generating Greater Value from IS Research," Data Base, accepted on Nov. 8, 2019.

[35] C. Bereiter, Education and mind in the knowledge age. Routledge, 2005.

[36] P. Diebold and M. Dahlem, "Agile practices in practice: a mapping study," 18th Conference on Evaluation and Assessment in Software Engineering, ACM, 2014.

[37] R. Shah and P.T. Ward, "Lean manufacturing: context, practice bundles, and performance," Journal of operations management, 21(2), 2003. pp. 129-149.

[38] S. Gregor, "The nature of theory in information systems. MIS Quarterly, 30 (3) 2006, pp. 611-642.

[39] E. B. Swanson and N. C. Ramiller, "The organizing vision in information systems innovation." Organization Science, 8(5), 1997, pp. 458-474. 
Table 2. Examples of resources, actions, characteristics, and areas of performance for sociotechnical WSs

\begin{tabular}{|c|c|c|c|c|}
\hline & \multicolumn{4}{|c|}{-------- Type of Concept } \\
\hline & Resource & Action & Characteristic & Area of Perf. \\
\hline $\begin{array}{l}\text { Work system as } \\
\text { a whole }\end{array}$ & $\begin{array}{l}\text { Time, Physical space } \\
\text { (location), Virtual space, } \\
\text { Capabilities }\end{array}$ & $\begin{array}{l}\text { Design, Develop, } \\
\text { Implement, Operate, } \\
\text { Modify }\end{array}$ & $\begin{array}{l}\text { Scalability, Flexibility, } \\
\text { Resilience, Fit/Misfit, } \\
\text { Centralization }\end{array}$ & $\begin{array}{l}\text { Cost to operate, } \\
\text { Recovery time after } \\
\text { an incident }\end{array}$ \\
\hline Customers & $\begin{array}{l}\text { Direct customers, } \\
\text { Indirect customers, } \\
\text { Other stakeholders }\end{array}$ & $\begin{array}{l}\text { Request, Receive } \\
\text { Co-produce, } \\
\text { Co-create value }\end{array}$ & $\begin{array}{l}\text { Customer priority } \\
\text { Customer significance } \\
\text { Customer loyalty }\end{array}$ & $\begin{array}{l}\text { Satisfaction, } \\
\text { Perception of quality }\end{array}$ \\
\hline $\begin{array}{l}\text { Product/ } \\
\text { services }\end{array}$ & $\begin{array}{l}\text { Components: Physical/ } \\
\text { informational/ service }\end{array}$ & $\begin{array}{l}\text { Design, Produce, Co- } \\
\text { produce, Deliver }\end{array}$ & $\begin{array}{l}\text { Complexity, Ease of } \\
\text { use, Fit to need }\end{array}$ & $\begin{array}{l}\text { Cost, Usability, } \\
\text { Value, Reliability }\end{array}$ \\
\hline $\begin{array}{l}\text { Processes and } \\
\text { activities }\end{array}$ & $\begin{array}{l}\text { Process, Activity } \\
\text { Trigger, Pre-condition, } \\
\text { Post-condition }\end{array}$ & $\begin{array}{l}\text { Initiate, Execute, } \\
\text { Complete, Work } \\
\text { around }\end{array}$ & $\begin{array}{l}\text { Degree of structure, } \\
\text { Complexity, Rhythm, } \\
\text { Vulnerability }\end{array}$ & $\begin{array}{l}\text { Efficiency, Activity } \\
\text { rate, Error rate, } \\
\text { Completion time }\end{array}$ \\
\hline Participants & $\begin{array}{l}\text { Users, Managers, } \\
\text { Support staff, } \\
\text { Stakeholders }\end{array}$ & $\begin{array}{l}\text { Perform roles, Use } \\
\text { tools, Receive training }\end{array}$ & $\begin{array}{l}\text { Knowledge, Skills, } \\
\text { Goals, Ambitions, } \\
\text { Certifications }\end{array}$ & $\begin{array}{l}\text { Job performance, } \\
\text { Job satisfaction, } \\
\text { Burnout rate }\end{array}$ \\
\hline Information & $\begin{array}{l}\text { Transaction data. Plan, } \\
\text { Goal, Business rule, } \\
\text { Text, Image, Video }\end{array}$ & $\begin{array}{l}\text { Capture, Transmit, } \\
\text { Store, Retrieve, } \\
\text { Manipulate, Display }\end{array}$ & $\begin{array}{l}\text { Precision, Age, } \\
\text { Traceability, Ease of } \\
\text { access, Source }\end{array}$ & $\begin{array}{l}\text { Accuracy, } \\
\text { Timeliness, } \\
\text { Access time }\end{array}$ \\
\hline Technologies & $\begin{array}{l}\text { Tools (used by people), } \\
\text { Automated services } \\
\text { (autonomous) }\end{array}$ & $\begin{array}{l}\text { Adopt, Test, Install, } \\
\text { Use, Update, Repair, } \\
\text { Calibrate }\end{array}$ & $\begin{array}{l}\text { Capabilities, Ease of } \\
\text { use, Interoperability } \\
\text { Price/performance }\end{array}$ & $\begin{array}{l}\text { Operating cost, } \\
\text { Uptime, Time to } \\
\text { repair }\end{array}$ \\
\hline Environment & $\begin{array}{l}\text { Culture, history, politics, } \\
\text { policies } \\
\text { Laws and regulations }\end{array}$ & $\begin{array}{l}\text { Sense environment, } \\
\text { Respond to } \\
\text { environment }\end{array}$ & $\begin{array}{l}\text { Fit with environment, } \\
\text { Vulnerability to } \\
\text { external threats }\end{array}$ & $\begin{array}{l}\text { Environment } \\
\text { awareness, } \\
\text { responsiveness }\end{array}$ \\
\hline Infrastructure & $\begin{array}{l}\text { Human/ technical/ } \\
\text { informational } \\
\text { infrastructure }\end{array}$ & $\begin{array}{l}\text { Request or use support } \\
\text { from infrastructure }\end{array}$ & $\begin{array}{l}\text { Capability, Capacity, } \\
\text { Availability. Ease of } \\
\text { use }\end{array}$ & $\begin{array}{l}\text { Uptime, Flexibility, } \\
\text { Availability, } \\
\text { Responsiveness }\end{array}$ \\
\hline Strategies & $\begin{array}{l}\text { Enterprise strategies, } \\
\text { Department strategies, } \\
\text { Work system strategies }\end{array}$ & $\begin{array}{l}\text { Create, Apply, } \\
\text { Negotiate, } \\
\text { Disseminate }\end{array}$ & $\begin{array}{l}\text { Appropriateness, } \\
\text { Fit with other strategies }\end{array}$ & $\begin{array}{l}\text { Frequency of } \\
\text { compliance and } \\
\text { noncompliance }\end{array}$ \\
\hline
\end{tabular}

Table 3: Examples of phenomena frequently relevant to sociotechnical WSs

\begin{tabular}{|l|l|}
\hline $\begin{array}{l}\text { Work system as } \\
\text { a whole }\end{array}$ & $\begin{array}{l}\text { Internal interactions, Interactions and overlaps with other WSs, Forces that affect WSs, Workarounds, } \\
\text { Vulnerabilities, Capabilities, Emergent change, Digitization, Risk, Compliance and Noncompliance }\end{array}$ \\
\hline Customers & Customer responsibility, Customer engagement, Customer experience, Customer visibility \\
\hline $\begin{array}{l}\text { Product/ } \\
\text { services }\end{array}$ & $\begin{array}{l}\text { Functions performed for other WSs, Servitization, Personalization, Customization, Mass customization, } \\
\text { Value co-creation, Value-in-use, Self-service }\end{array}$ \\
\hline $\begin{array}{l}\text { Processes and } \\
\text { activities }\end{array}$ & $\begin{array}{l}\text { Regulation of activities, Division of labor, Coordination, Outsourcing, Leanness, Coherence, } \\
\text { Workarounds, Operating across time zones, Loose vs. tight coupling }\end{array}$ \\
\hline Participants & Work/life balance, Techno-stress, Information overload, Micromanagement, Burnout \\
\hline Information & Missing data, Inconsistent data, Obsolete data, Bias, Value of information, Information decay \\
\hline Technologies & Affordances, Obsolescence, Platforms, Use vs. misuse, Loose vs. tight coupling \\
\hline Environment & Turbulence, Technological change, Demographic shifts, Competitive challenges \\
\hline Infrastructure & Enterprise integration, Network effects, Shared resources, Resource integration \\
\hline Strategies & Alignment with strategy, Mission creep, Digital strategy \\
\hline
\end{tabular}

Table 4: Ideas associated with making decisions, one of 18 facets of processes and activities

\begin{tabular}{|l|l|}
\hline $\begin{array}{l}\text { Associated } \\
\text { concepts }\end{array}$ & $\begin{array}{l}\text { Decision, criteria, alternative, value, risk, payoff, utility, utility function, tradeoff, projection, } \\
\text { optimum, satisficing vs. optimizing, heuristic, probability, distribution of results, risk aversion }\end{array}$ \\
\hline Evaluation criteria & $\begin{array}{l}\text { Actual decision outcomes, realism of projected decision outcomes, riskiness, decision participation, } \\
\text { concurrence, ease of implementation }\end{array}$ \\
\hline Design trade-offs & $\begin{array}{l}\text { Quick responsiveness vs. superficiality, Complexity and precision of models vs. understandability, } \\
\text { Brevity vs. omission of important details }\end{array}$ \\
\hline Sub-facets & $\begin{array}{l}\text { Defining the problem; identifying decision criteria; gathering relevant information; analyzing the } \\
\text { information; defining alternatives; selecting among alternatives; explaining the decision }\end{array}$ \\
\hline
\end{tabular}

